\title{
Note on Pseudonyms
}

In order to protect the identity of the people whose lives are discussed in this book, I have chosen to give each person a pseudonym, designated by a letter of the alphabet. These letters were chosen randomly: Ivan Ivanovich Ivanov might be labeled "Comrade O" or "Comrade Z," for example, depending on my whim as I was writing the chapter in which he appeared. In some archives, I was not allowed to copy down the names of the people whose case files I read, and in these instances, it is possible that I have accidentally assigned a Communist his own initial as a pseudonym.

I have tried both to assign an individual pseudonym to every Communist whose case I discussed in detail and to limit each letter of the alphabet to one use per chapter. Although I made an effort to ensure that Communists whose misconduct was discussed in multiple chapters received the same pseudonym each time they appeared, readers should not assume that two Communists designated the same way were the same person. In other words, a Communist described as Comrade $Z$ in chapter 1 will be different from one described as Comrade $Z$ in chapter 2 , unless I explicitly note otherwise.

I have included the real names of Soviet citizens on a few occasions, most often in chapter 3. I did so only when their misconduct involved changing their names in order to hide their ethnicity (in which case I used only their first name and patronymic) or when they served in a major political office (and therefore qualify as public figures rather than private citizens). When I discussed the case of a Communist whose behavior was described in a newspaper article or in a document that has since been published, finally, I often used his or her actual name, since it was already in the public record. 
